\title{
Multiple element of miniaturized printed log-periodic second series koch dipole array antenna for wideband chipless RFID tag reader
}

\author{
Mohd Ezwan Bin Jalil ${ }^{1}$, Mohamad Kamal A Rahim ${ }^{2}$, Noor Asmawati Samsuri ${ }^{3}$, Sunti Tuntrakool ${ }^{4}$ \\ ${ }^{1,2,3}$ Advanced RF \& Microwave Research Group, School of Electrical Engineering, Faculty of Engineering, \\ Universiti Teknologi Malaysia, Malaysia \\ ${ }^{4}$ Faculty of Industrial Education and Technology, King Mongkut Institute of Technology Ladkrabang (KMITL), Thailand
}

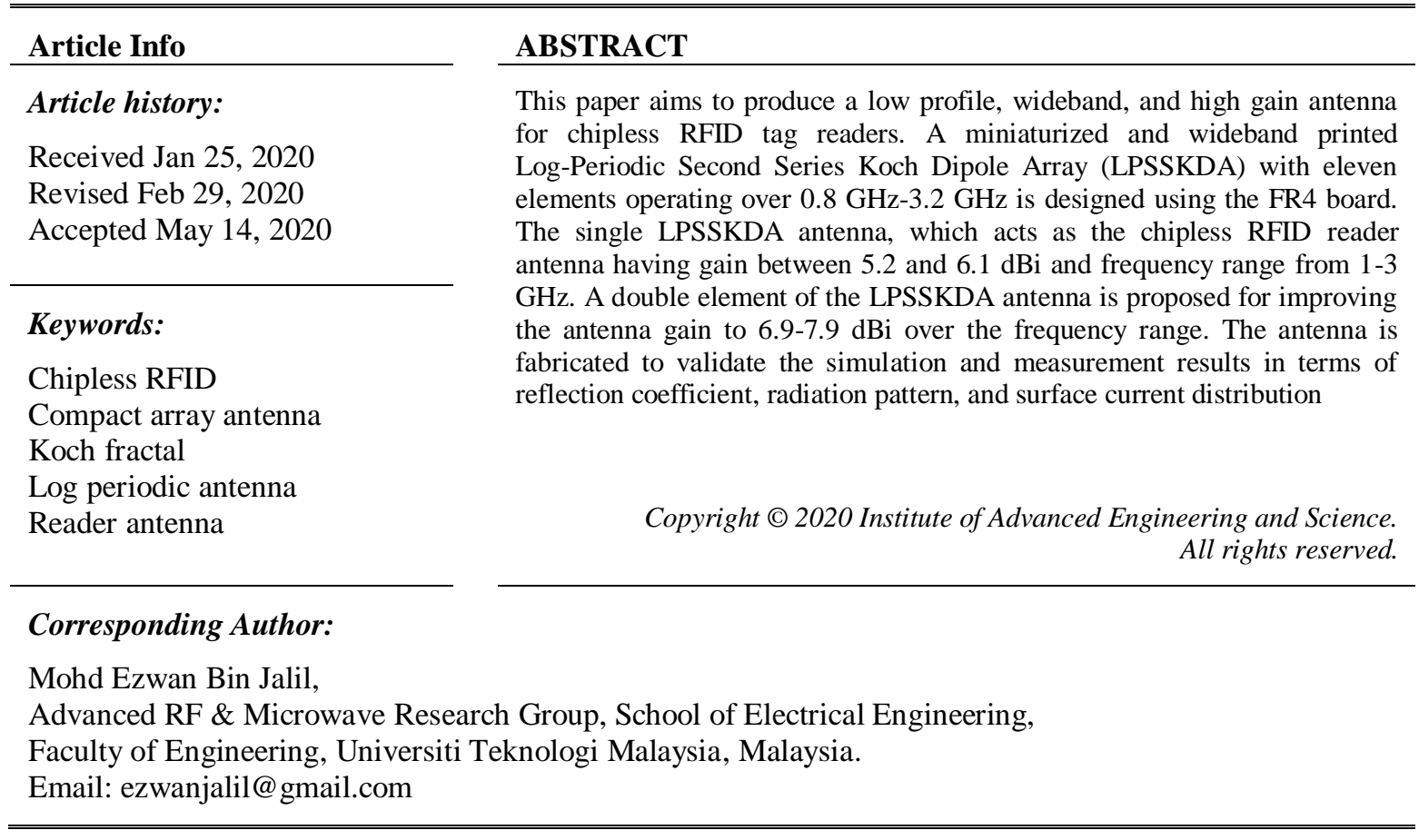

\section{INTRODUCTION}

Chipless Radio Identification (RFID) is wireless identification capturing data technology using transmission and reception of electromagnetic waves without a microchip [1, 2]. This microchip is called Application Specific Integrated (ASIC) Circuit for the application of product packaging, object tracking, inventory control and authentication activities [3]. The chipless RFID system can reduce complexity and minimize manufacturing and implementation cost the conventional chip RFID [4]. The chipless RFID can compete with commercial barcode technology with providing better performance in term capability of detection line of sight with obstacle and range distance and rate speed detection [5]. Many variations small size, high capacity, and printable chipless RFID based frequency domain and time domain have been designed to fulfill the requirement of the chipless RFID system [6, 7]. Most structure of chipless RFID structures has implemented microwave structure such as dipole arrays [8], trefoil resonator [9], microstrip resonator [10], radar cross-section (RCS) [11] and frequency-selective surface (FSS) [12] with various conductor layout, design and shape for coding identification. This innovative technology of chipless RFID with the integration of Internet of Thing (IoT) [13] including smart radio-frequency sensors [14], 5-G communication technologies [15] and cloud computing storage can offer an enormous potential to replace the conventional visual optical barcode and conventional RFID system [16]. Among them, the chipless RFID based frequency domain is more relevant due to the ability of high capacity data and minimum size structure. The chipless RFID system consists of a transponder, including an encoding element and tag antenna and reader system with a reader antenna, as shown in Figure 1. The reader antenna will transmit the signal to the transponder and receive back interrogation signal with information number. 


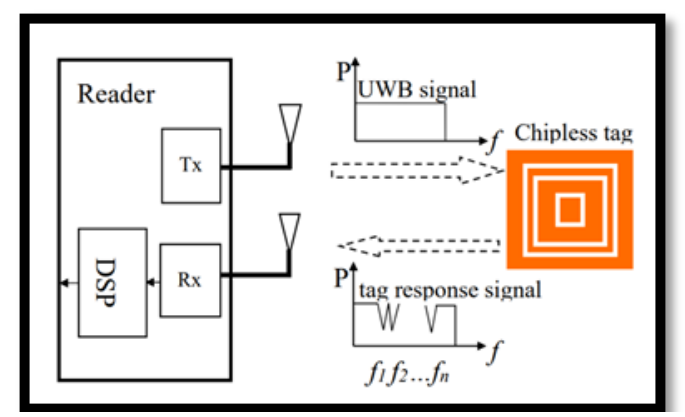

Figure 1. A proposed chipless RFID system with two reader antenna as transmitter and receiver [17]

One of the crucial elements of chipless RFID is a reader antenna [18] The reader antenna requires high bandwidth to maximize the data information capacity in the frequency range. Furthermore, small size, lightweight, rigid mobile reader antenna ensure the consistent behavior of $\left|S_{21}\right|$, the transmission coefficient of both reader antenna as data information results in facilitating the commercial user. Another requirement is a high gain antenna for increasing detection distance range and minimize power transmitted following maximum Effective Isotropic Radiated Power (EIRP) [19]. The Federal Communication Commission (FCC) will regulate the maximum EIRP for reducing the risk of RF interference with other systems. For example, M. A. Islam has designed $4 \times 4$ dual-polarized (DP) aperture-coupled millimeter (mm)-wave chipless RFID tag reader has for producing wide frequency range with high isolation performance with 16-dBi realized gain [20]. Besides, F Yang has produced a Vivaldi antenna operating between 3-6 GHz with boresight gain between $6-10.8 \mathrm{dBi}$ [21]. A new design of a $2 \times 2$ array of dipole reflector antenna is presented, producing a peak gain of $13.6 \mathrm{dBi}$ in the range frequency between $4.8-5.4 \mathrm{GHz}$ as shown in [22]. A. Islam introduces a single element linearly polarized (LP) aperture coupled microstrip patch antenna (ACMPA) in 6.5-10.6 GHz using Taconic TLX-8 with permittivity of 2.55[23]. M Zommoroddi proposes four-element of double-side printed dipole (DSPD) array antenna with a dimension of $22 \mathrm{~mm} \times 14 \mathrm{~mm}$ at 57-64 GHz around $12 \%$ bandwidth on Taconic TLX-8 substrate with permittivity of 2.25 as shown in [24]. Ihamji proposed a compact miniature fractal planar antenna for RFID reader with a dimension of $21 \mathrm{~mm} \times 52 \mathrm{~mm}$ operating between $2.27-2.68 \mathrm{GHz}$ [25]

A log-periodic antenna consisting of a half-wave dipole element is suitable for the proposed chipless RFID reader antenna due to its high gain, low cross-polarization, and wideband characteristic [26-28]. This multi-element directional antenna often works for wideband frequency applications. In this paper, a high gain Printed Log-Periodic Second Series Koch Dipole Array (LPSSKDA) is introduced operating between 1-3 GHz using FR4 substrate with permittivity of 5.3 and loss tangent of 0.025 at $2 \mathrm{GHz}$. The first iteration Koch Fractal series structure is introduced to miniaturize $16 \%$ the actual length of dipole length. Then, this research paper shows a double-element of log-periodic Koch Fractal array antenna to enhance gain for improvement distance range measurement. Lastly, this paper will present a comparative analysis of simulated and measured reflection coefficient, gain, and radiation pattern.

\section{ANTENNA DESIGN}

The proposed printed Log-Periodic Second Series Koch Dipole Array (LPSSKDA) antenna with eleven elements has been designed operating between 1-3 GHz using the FR4 substrate covering at Ultra High-Frequency (UHF) band as shown in Figure 2. The Koch Fractal log periodic antenna is created by substituting all series of conventional straight dipoles with Koch Fractal dipole with two series of triangle curves. There have three crucial parameters for designing a periodic log antenna that are geometric ratio, angle factor, and spacing factor, as shown in (1) and (2). The geometric ratio symbolized with $\tau$ determines the length, the spacing, the width, and the resonant frequency between elements of each dipole element using the scaling factor technique. The highest length dipole element determines the lowest resonance operating frequency and vice-versa. Table 1 shows all dimension parameters of the LPSSKDA with a symbol.

$$
\tau=\frac{l_{n}}{l_{n+1}}=\frac{w_{n}}{w_{n+1}}=\frac{f_{n}}{f_{n+1}}=\frac{d_{n}}{d_{n+1}}
$$

The spacing factor $\sigma$ is calculated using the following equation. The antenna bandwidth $B_{s}$ is defined to determine the number of element $N$. 


$$
\alpha=\tan ^{-1}\left[\frac{1-\tau}{4 \sigma}\right] \quad N=1+\frac{\ln \left(B_{S}\right)}{\ln \left(\frac{1}{\tau}\right)}
$$
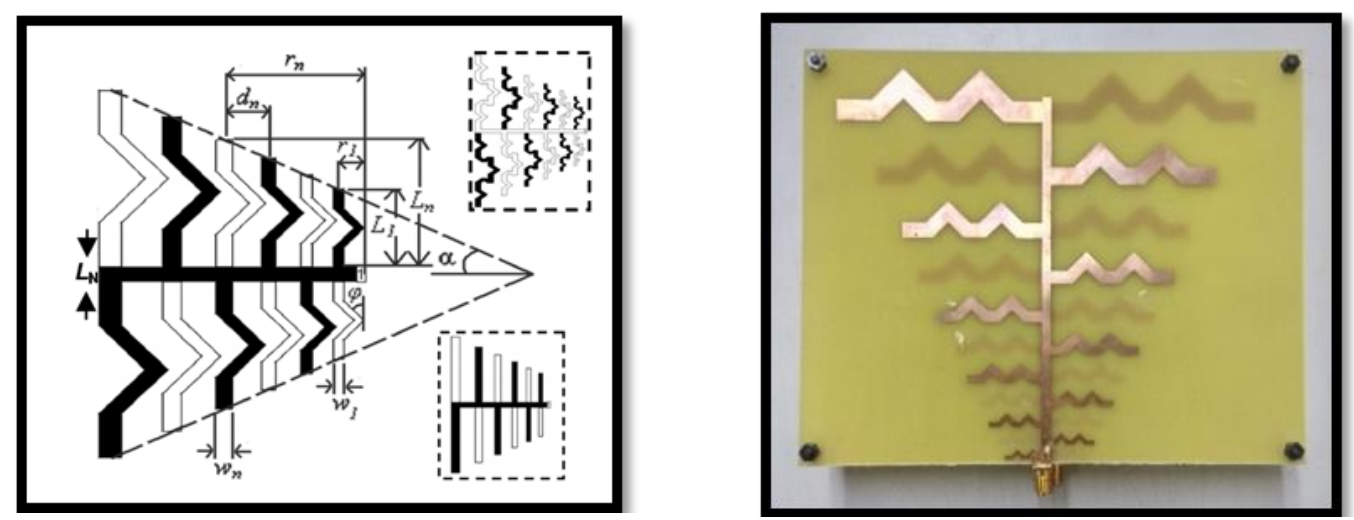

Figure 2. Log-periodic second series koch dipole array design and prototype

Table 1. Dimension parameter of printed log-periodic second series koch dipole array (LPSSKDA)

\begin{tabular}{ccc}
\hline Parameter & Symbol & $\mathrm{mm}$ \\
\hline Scaling factor & $\tau$ & 0.8 \\
Angle Factor & $\alpha$ & 34 \\
First Spacing Element & $d_{1}$ & 21.6 \\
First Length Element & $l_{1}$ & 140.0 \\
First Width Element & $w_{1}$ & 6.9 \\
\hline
\end{tabular}

\section{RESULTS AND ANALYSIS}

\subsection{Printed log-periodic second series koch dipole array (LPSSKDA)}

The LPSSKDA antenna prototype has been fabricated and measured to recognize the simulation design validity. Figure 3 shows the simulation result of the reflection coefficient of the simulated and measured LPSSKDA with a flare angle of 45 degrees. The log-periodic antenna with an optimized eleven dipole element performs well with the bandwidth of $2400 \mathrm{HZ}$. The reflection coefficient of the fabricated LPSSKDA antenna performs well and valid with the simulation operating frequency between $0.8-3.2 \mathrm{GHz}$. The multiple Koch dipole elements form numerous deep resonant in the frequency range. Figure 4 shows the surface current distribution for two different resonant frequencies at 1 and $3 \mathrm{GHz}$. At the low operating frequency of $1 \mathrm{GHz}$, the surface current propagates well at the second, third, and forth the dipole elements. At the high operating frequency of $3 \mathrm{GHz}$, the surface current consistently flow with high density at the small element of ninth, tenth and eleventh element.

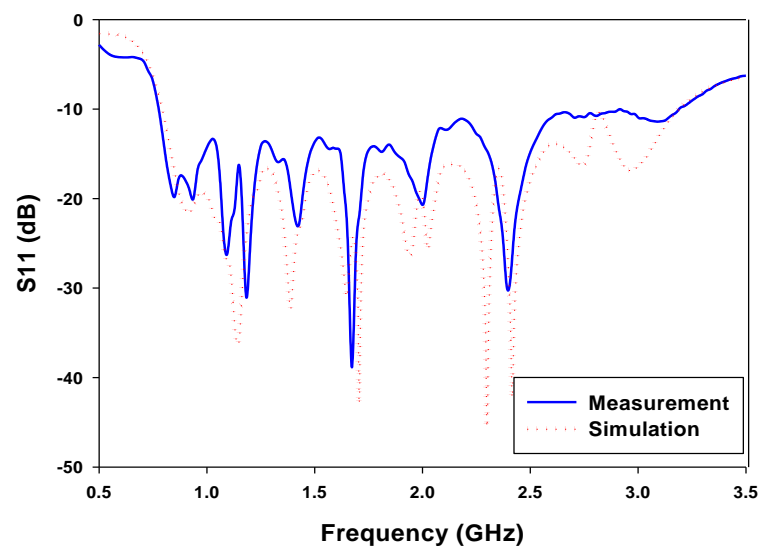

Figure 3. Simulation and measurement result of the reflection coefficient the log-periodic second series koch dipole array 

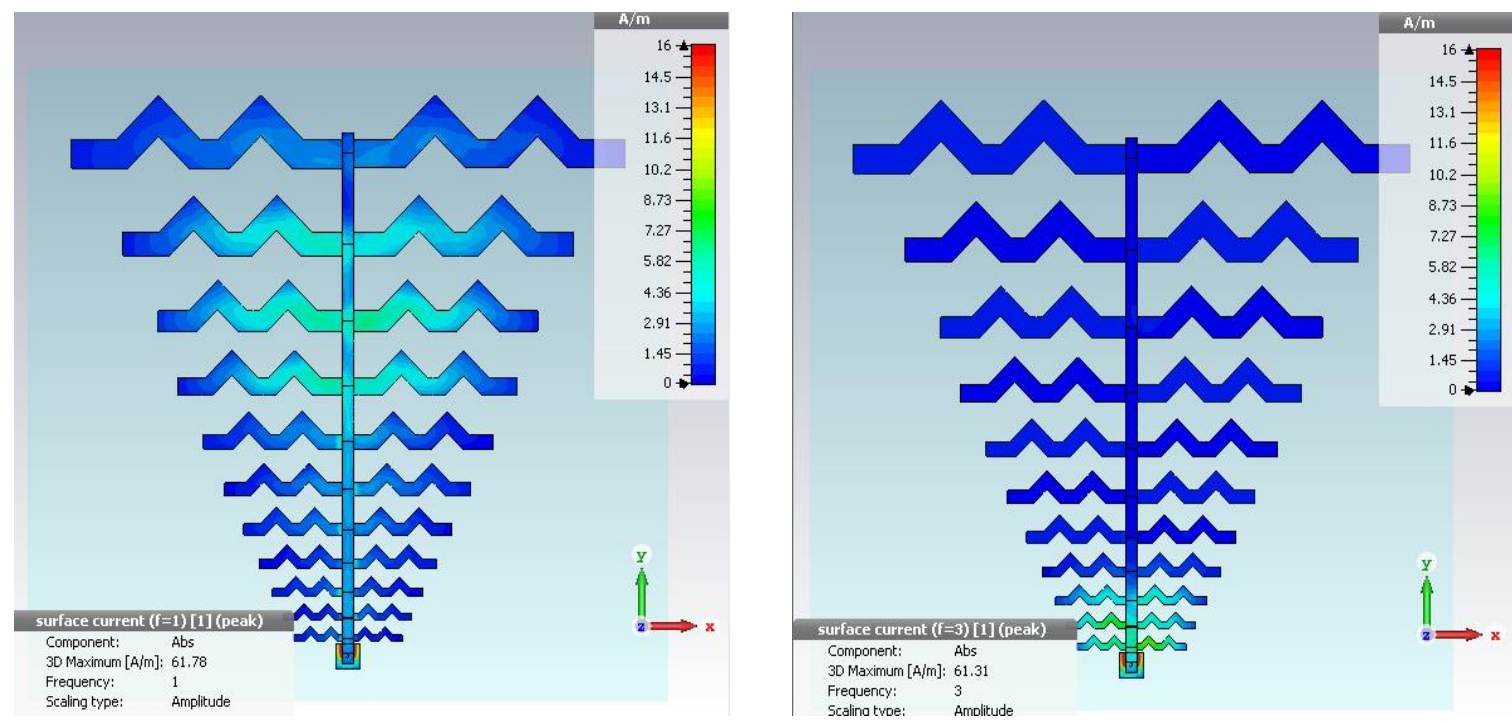

Figure 4. The current distribution of log-periodic second series koch dipole array antenna at $1 \mathrm{GHz}$ and $3 \mathrm{GHz}$

\subsection{Double element of printed log-periodic second series koch dipole array (LPSSKDA)}

The double element of LPSSKDA antennas is placed with a vertical position by connecting with the planar power divider to improve the gain enhancement of antenna, as shown in Figure 5. Initially, the LPSSKDA antenna has gain between 5.2-6.1 dB in range frequency between 1-3 $\mathrm{GHz}$ with the backward directional pattern. The arrangement of two elements of LPSSKDA improves the antenna gain to 6.9-7.9 dB with maintaining an average half-power beamwidth pattern of 69 degrees. Figure 6 depicts the E-field radiation pattern of the LPSSKDA antenna with the single and double element at 1 and $3 \mathrm{GHz}$. For a single element, the front-to-back (FTB) ratios are around $11.8 \mathrm{~dB}$ at $1 \mathrm{GHz}$ and $13.3 \mathrm{~dB}$ at $3 \mathrm{GHz}$. The FTB has been changed around $14.0 \mathrm{~dB}$ at $1 \mathrm{GHz} 13.0 \mathrm{~dB}$ at $3 \mathrm{GHz}$ by adding a double element of the LPSSKDA antenna. Table 2 shows the comparative performance between the first and double elements of the LPSSKDA at 1, 2 and $3 \mathrm{GHz}$. The double element of the LPSSKDA improve the antenna gain and reduce the half-power beamwidth at $1-3 \mathrm{GHz}$ with maintaining FTB compared to the first element of the LPSSKDA.
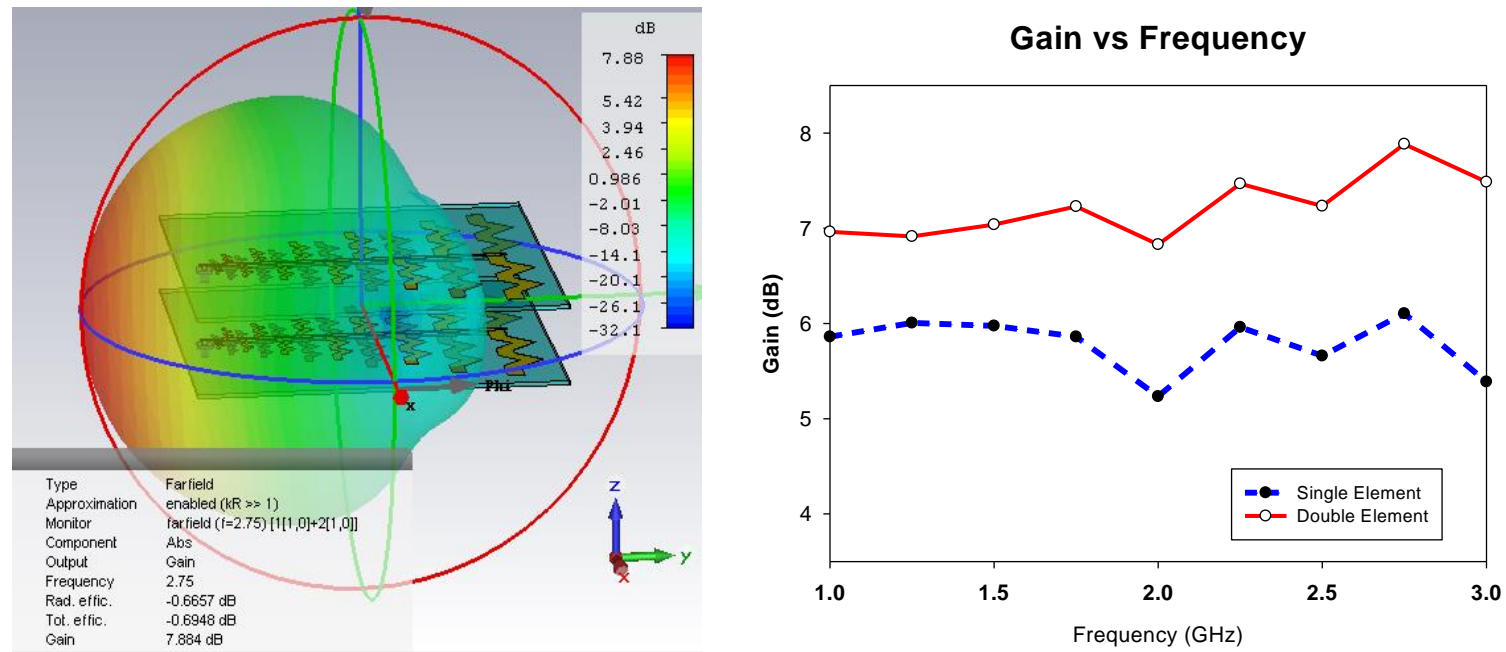

Figure 5. 3D radiation pattern of double element log-periodic second series koch dipole array and gain comparison of single and double element of log-periodic second series koch dipole array 

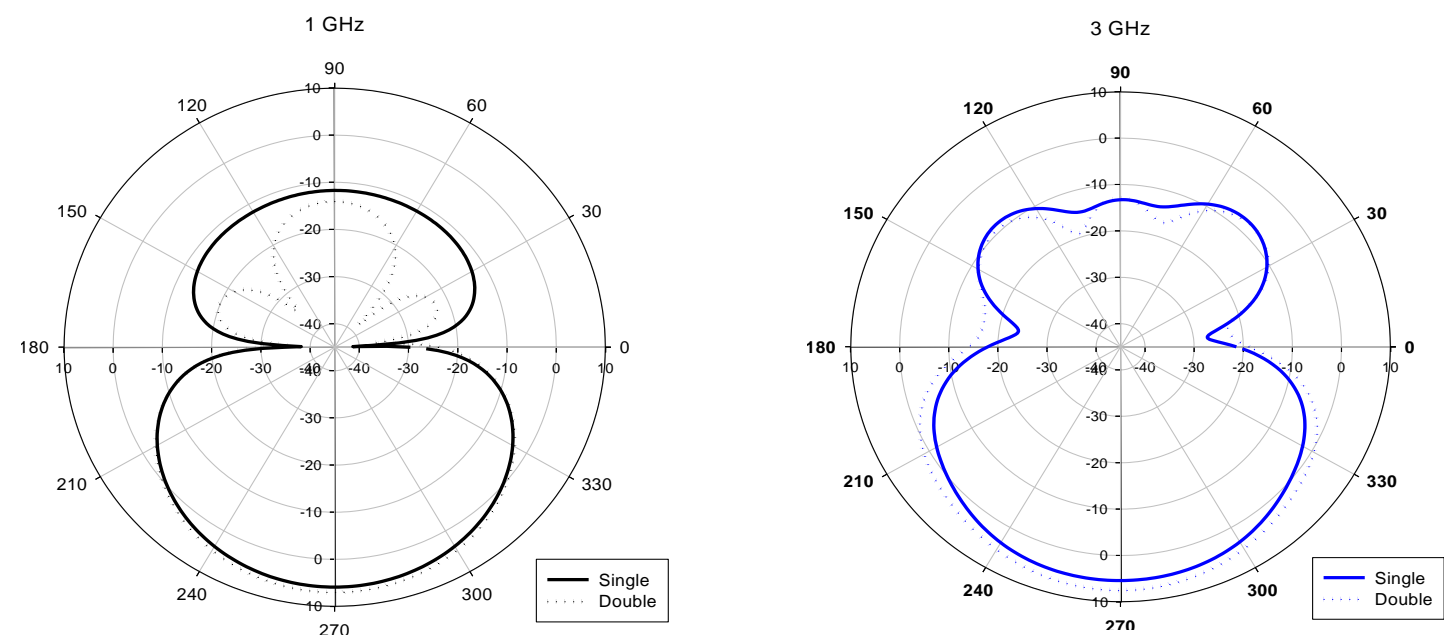

Figure 6. The simulated radiation pattern of E-plane of single and double element log-periodic second series koch dipole array at $1 \mathrm{GHz}$ and $3 \mathrm{GHz}$

Table 2. Comparison between a single and double element of the LPSSKDA antenna

\begin{tabular}{|c|c|c|c|}
\hline \multicolumn{2}{|c|}{ Operating Frequency } & $\begin{array}{c}\text { Single } \\
0.77-3.18\end{array}$ & $\begin{array}{c}\text { Double } \\
0.80-3.15\end{array}$ \\
\hline \multirow{3}{*}{ Gain $\quad(\mathrm{dBi})$} & $1 \mathrm{GHz}$ & 5.86 & 6.96 \\
\hline & $2 \mathrm{GHz}$ & 5.23 & 6.83 \\
\hline & $3 \mathrm{GHz}$ & 5.38 & 7.49 \\
\hline \multirow[t]{3}{*}{ Front-to-back ratio $(\mathrm{dB})$} & $1 \mathrm{GHz}$ & 11.75 & 14.05 \\
\hline & $2 \mathrm{GHz}$ & 14.73 & 11.73 \\
\hline & $3 \mathrm{GHz}$ & 13.03 & 13.31 \\
\hline \multirow[t]{3}{*}{ Half-power beam width (degree) } & $1 \mathrm{GHz}$ & 71.2 & 68.6 \\
\hline & $2 \mathrm{GHz}$ & 73.1 & 70.8 \\
\hline & $3 \mathrm{GHz}$ & 76.2 & 74.4 \\
\hline
\end{tabular}

The simulated and measured pattern of LPSSKDA with the double element is very similar and directive, as shown in Figure 7 for E-plane pattern and Figure 8 for the H-plane pattern. The half-power beamwidth is about in the range of 68-74 degrees from $1 \mathrm{GHz}$ up to more $3 \mathrm{GHz}$. Measured side lobe level ranges from $-15 \mathrm{dBi}$ to less than $-35 \mathrm{dBi}$ at $1 \mathrm{GHz}$ and from $-7 \mathrm{dBi}$ to less than $-20 \mathrm{dBi}$ as expected the same trend with the simulated result. The presence of a power divider for connecting two LPSSKDA antennas interrupted the central radiation portion of the antenna, causing a difference in the sidelobe level in measurement and simulation.
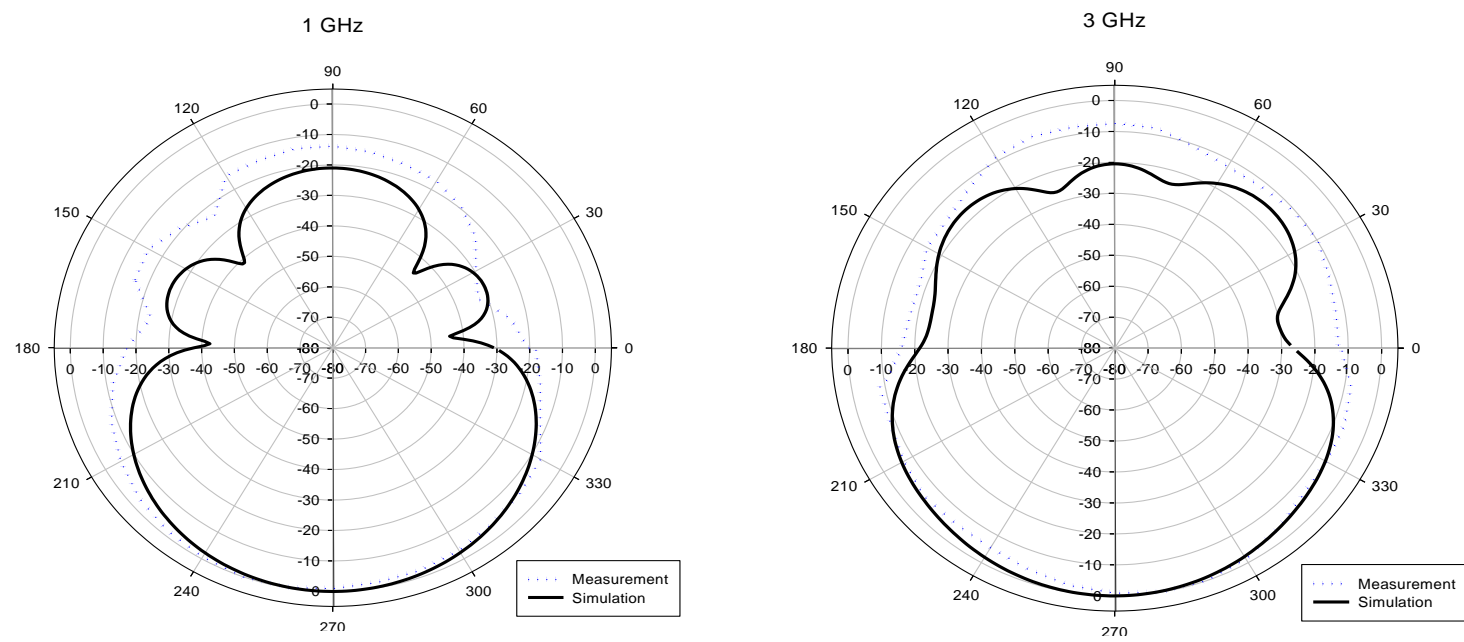

Figure 7. Simulated and measured E-plane result of normalized radiation pattern result at $1 \mathrm{GHz}$ and $3 \mathrm{GHz}$

Multiple element of miniaturized printed log-periodic second series koch dipole.... (Mohd Ezwan Bin Jalil) 

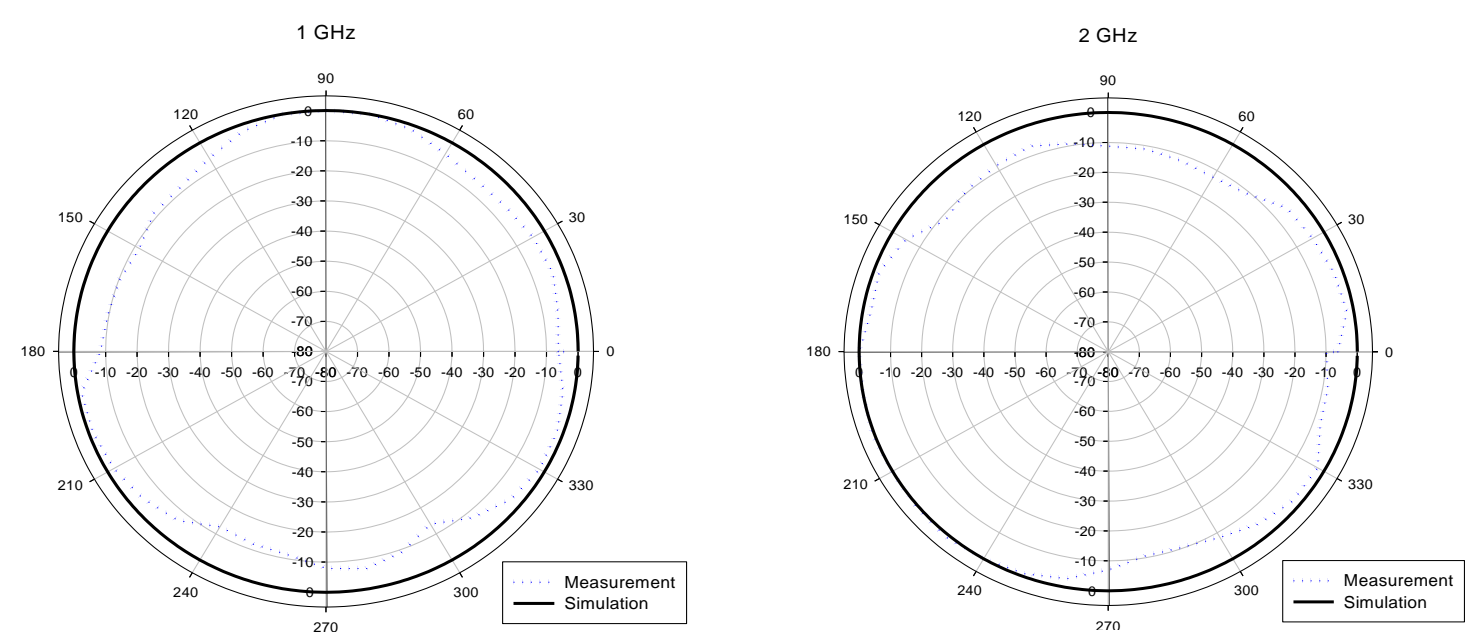

Figure 8. Simulated and measured $\mathrm{H}$-plane result of normalized radiation pattern result at $1 \mathrm{GHz}$ and $3 \mathrm{GHz}$

Figure 9 shows the measured radiation pattern of the LPSSKDA antenna with a different resonant frequency. The main beamwidth has a similar radiation pattern with different resonant frequencies at 1,2 , and $3 \mathrm{GHz}$. However, the side lobe range for the low frequency is less than $-14 \mathrm{~dB}$ compared to the high frequency of less than $-5 \mathrm{~dB}$.
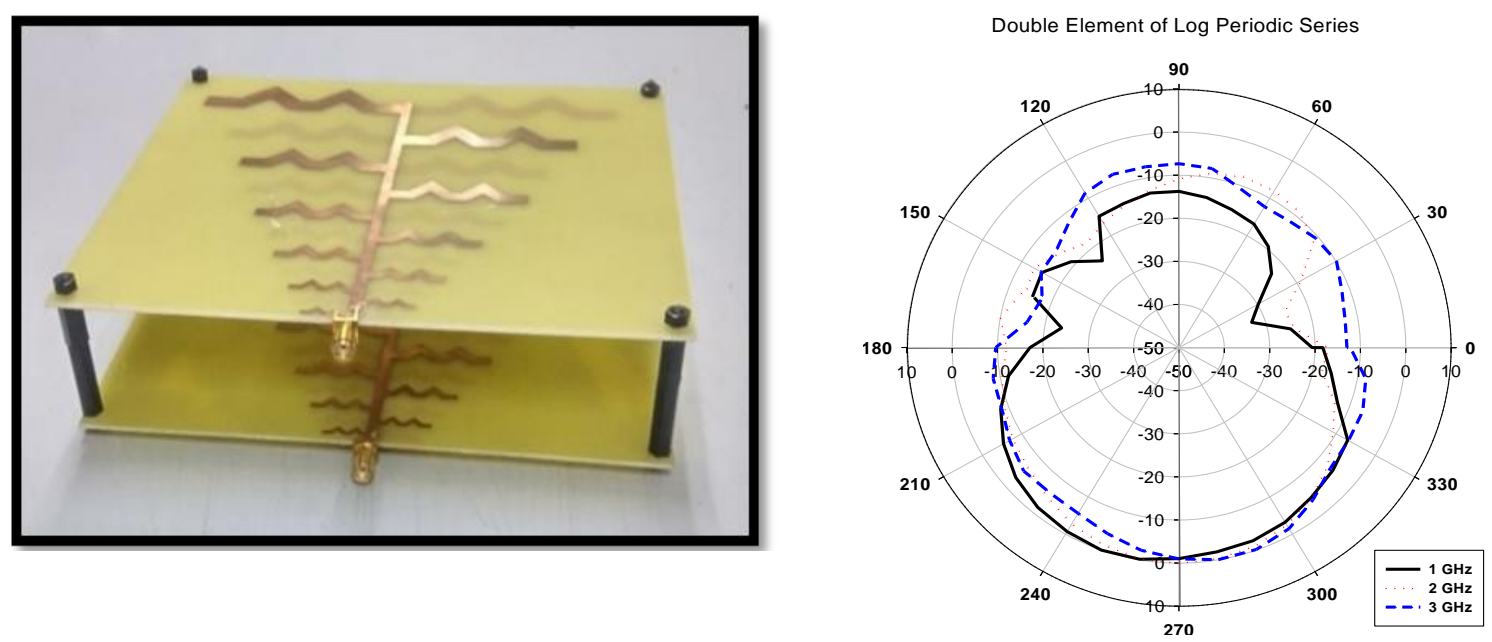

Figure 9. The double element of log-periodic second series koch dipole array and measured E-plane radiation pattern of the double element of the log-periodic second series koch dipole array

\section{CONCLUSION}

A high gain, high bandwidth, and miniaturized Koch Fractal Log Periodic Antenna with eleven elements have been designed, simulated, and fabricated to miniaturize $15 \%$ of the length of the conventional straight dipole log-periodic antenna. Then, the miniaturized double element of the log-periodic antenna series. This paper proposes the double elements of the Log-Periodic Second Series Koch Dipole Array with the gain between 6.8-7.9 $\mathrm{dB}$ in the range between 1-3 GHz as a chipless reader antenna. For future work, two of the logperiodic Koch Fractal with the double element are positioned with opposite directions each other to identify the data information of chipless RFID tag based on the transmission coefficient between the two antennas

\section{ACKNOWLEDGEMENTS}

The authors would like to thank the Ministry of Education (MOE), School of Postgraduate Studies (SPS), Research Management Centre, Advanced RF and Microwave Research Group, School of Electrical 
Engineering and Universiti Teknologi Malaysia (UTM), Johor Bahru, for the support of the research under Grant 06G15 and 04G67. The authors also would like to acknowledge all members of the Advanced RF and Microwave Research Group (ARFMRG).

\section{REFERENCES}

[1] S. Preradovic and N. C. Karmakar, "Chipless RFID: Bar code of the future," IEEE Microwave Magazine, vol. 11, no. 7, pp. 87-97, 2010.

[2] M. E. B. Jalil, et al., "Flexible ultra-wideband antenna incorporated with metamaterial structures: multiple notches for chipless RFID application, Appled Physhic A, vol. 123, no. 1, pp. 48, 2017.

[3] C. Scherjon, "RFID transponders," in J. Burghartz (ed), "Ultra-thin Chip Technology and Applications, Springer Science+Business Media, pp. 389-398, 2011.

[4] S. Preradovic and N. C. Karmakar, "Design of chipless RFID tag for operation on flexible laminates," IEEE Antennas Wireless and Propagation Letters, vol. 9, pp. 207-210, 2010.

[5] M. A. Islam and N. Karmakar, "On a compact printable dual-polarized chipless RFID tag using slot length variation encoding technique for barcode replacement," 2015 IEEE MTT-S International Microwave Symposium, pp. 1-4, 2015.

[6] M. E. B. Jalil, et al., "Size miniaturization of chipless RFID tag using metamaterial structure," Indonesia Journal of Electrical Engineering and Computer Science, vol. 15, no. 2, pp. 723-732, 2019.

[7] A. Vena, et al., "Chipless RFID tag using hybrid coding technique," IEEE Transactions on Microwave Theory and Techniques, vol. 59, no. 12, pp. 3356-3364, 2011.

[8] M. Svanda, et al., "Platform Tolerant, High Encoding Capacity Dipole Array-Plate Chipless RFID Tags," IEEE Access, vol. 7, pp. 138707-138720, 2019.

[9] N. Tariq, et al., "Orientation Independent Chipless RFID Tag Using Novel Trefoil Resonators," IEEE Access, vol. 7, pp. 122398-122407, 2019.

[10] H. Li, et al., "Design and Analysis of Chipless RFID Tags Based on Retro-Radiators," IEEE Access, vol. 7, pp. 148208-148217, 2019.

[11] I. Balbin and N. C. Karmakar, "Phase-encoded chipless RFID transponder for large-scale low-cost applications," IEEE Microwave and Wireless Components Letters, vol. 19, no. 8, pp. 509-511, 2009.

[12] F. Costa, et al., “A Robust Differential-Amplitude Codification for Chipless RFID," IEEE Microwave and Wireless Components Letters, vol. 25, no. 12, pp. 832-834, 2015.

[13] S. A. W. Al-Abassi, et al., "Smart prepaid traffic fines system using RFID, IoT and mobile app," TELKOMNIKA Telecommunication, Computing, Electronics and Control, vol. 17, no. 4, pp. 1828-1837, 2019.

[14] S. Shrestha, et al., "A chipless RFID sensor system for cyber centric monitoring applications," IEEE Transactions on Microwave Theory and Techniques, vol. 57, no. 5, pp. 1303-1309, 2009.

[15] J. G. D. Hester and M. M. Tentzeris, "A Mm-wave ultra-long-range energy-autonomous printed RFID-enabled vanatta wireless sensor: At the crossroads of 5G and IoT," IEEE MTT-S International Microwave Symposiu, pp. 1557-1560, 2017.

[16] F Zheng, Y Chen, T Kaiser and A. J. H. Vinck, "On the Coding of Chipless Tag" IEEE Journal of Radio Frequency Identification, vol. 2, no. 4, pp. 170-183, 2018.

[17] Z. Ma and Y. Jiang, "High-Density 3D Printable Chipless RFID Tag with Structure of Passive Slot Rings," Sensors, vol. 19, no. 11, pp. 2535-2552, 2019.

[18] M. A. Islam, et al., "A Novel Compact Chipless RFID Tag and Near-Field Reader," Asia-Pacific Microwave Conferene 2011, vol. 1, pp. 1518-1521, 2011.

[19] N. C. Karmaker, "Tag, You're It Radar Cross Section of Chipless RFID Tags," IEEE Microwave Magazine, vol. 17, no. 7, pp. 64-74, 2016.

[20] M. A. Islam and N. C. Karmakar, "A $4 \times 4$ dual polarized mm-wave ACMPA array for a universal mm-wave chipless RFID tag reader," IEEE Transactions on Antennas and Propagation, vol. 63, no. 4, pp. 1633-1640, 2015.

[21] Y. F. Weng, et al., "Design of chipless UWB RFID system using A CPW multi-resonator," IEEE Antennas and Propagation Magazine, vol. 55, no. 1, pp. 13-31, 2013.

[22] R. Koswatta and N. C. Karmakar, "Investigation into antenna performance on read range improvement of chipless RFID tag reader," 2010 Asia-Pacific Microwave Conference, pp. 1300-1303, 2010.

[23] M. A. Islam and N. Karmakar, "A linearly polarized (LP) Reader antenna for lp and orientation insensitive (OI) chipless RFID tags," Proceedings of 9th International Conference on Electrical and Computer Engineering (ICECE 2016), pp. 431-434, 2016.

[24] M. Zomorrodi and N. C. Karmakar, "Chipless RFID Reader: Low-cost wideband printed dipole array antenna," IEEE Antennas and Propagation Magazine, vol. 57, no. 5, pp. 18-29, 2015.

[25] M. Thamji, et al., "A compact miniature fractal planar antenna for RFID readers," Indonesia Journal of Electrical Engineering and Computer Science, vol. 15, no. 1, pp. 300-305, 2019.

[26] N. S. M. Yaziz, et al., "Second iteration of slotted fractal log periodic dipole antenna (LPDA)," 2017 International Symposium on Antennas and Propagation (ISAP 2017), pp. 1-2, 2017.

[27] R. Lehmensiek and D. I. L. de Villiers, "Optimization of log-periodic dipole array antennas for wideband omnidirectional radiation," IEEE Transactions on Antennas and Propagation, vol. 63, no. 8, pp. 3714-3718, 2015.

[28] G. Zhai, et al., "Gain enhancement of printed log-periodic dipole array antenna using director cell," IEEE Transactions on Antennas and Propag., vol. 62, no. 11, pp. 5915-5919, 2014. 